\title{
Identificação de polimorfismos de genes candidatos nos transtornos alimentares
}

\section{Identification of candidate gene polymorphisms in eating disorders}

\author{
Felícia B. Sarrassini ${ }^{1}$, José E. dos Santos², Rosane P. P. Ribeiro ${ }^{3}$
}

\begin{abstract}
RESUMO
Objetivo: Identificar polimorfismos (SNPs) dos genes 5-HT ${ }_{2 \mathrm{~A}}$, BDNF e ERâ em 29 pacientes com transtornos alimentares (TAs) e 78 mulheres saudáveis junto a um serviço especializado. Metodologia: Foram coletados dados de idade, peso e estatura para cálculo do Índice de Massa Corporal, aplicado o Eating Attitudes Test (EAT-26) e determinado os SNPs dos participantes. As frequências alélicas e genotípicas dos genes foi calculada e realizada a análise que unia genótipos que possuíam alelos de risco para cada gene. Resultados: Não houve diferença significativa na idade, no estado nutricional e na presença dos alelos de risco entre os grupos $\left(5 \mathrm{HT}_{2 \mathrm{~A}}\right.$ : OR=1,964; BDNF: OR=1,120; ERb éxon 5: OR=0,751 e éxon 8: $\mathrm{OR}=0,380)$. Conclusão: A heterogeneidade da população brasileira, a baixa incidência da doença e a pequena amostra podem ter exercido influência nos resultados sendo necessários futuros estudos para elucidar o papel da genética na etilogia dos TAs.
\end{abstract}

Palavras-chave: Transtornos da Alimentação. Polimorfismo Genético. Genes. Anorexia Nervosa. Bulimia Nervosa.

\section{Introdução}

A anorexia nervosa (AN) e a bulimia nervosa (BN) são transtornos alimentares (TAs) de origem psiquiátrica que afetam adolescentes e adultos jovens do sexo feminino. Podem evoluir para quadros graves devido aos prejuízos biológicos e psicológicos, além de aumento na morbimortalidade. ${ }^{1}$

A etiologia sugere um modelo multifatorial envolvendo aspectos biológicos, psicológicos, socioculturais e familiares, e a genética mostra-se uma área promissora de investigação a partir dos resultados de três genes avaliados. ${ }^{2,3}$

Um deles é o codificador do receptor da 5-hidroxitriptamina ou serotonina $\left(5-\mathrm{HT}_{2 \mathrm{~A}}\right)^{4-7}$, cujo polimorfismo de nucleotídeo simples (Single Nucleotide Polymorphism -SNP) (5- $\left.\mathrm{HT}_{2 \mathrm{~A}} ; 1438 \mathrm{G} / \mathrm{A}\right)$ apresenta associação à redução de energia com tendência à menor ingestão de macronutrientes. ${ }^{8}$ Em pacientes com AN do subtipo restritivo (AN-R), há propensão para o aumento do nível dessa substância. ${ }^{9}$

Outro gene é o codificador do fator neurotrófico
1. Nutricionista, Universidade de Franca - UNIFRAN. Doutora em Ciências em Saúde Pública pela EERP-USP.

2. Docente da Divisão de Nutrologia, Departamento de Clínica Médica, Faculdade de Medicina de Ribeirão Preto - USP

3. Docente do Departamento de Enfermagem Materno-Infantil e Saúde Pública. Escola de Enfermagem de Ribeirão Preto USP
CORRESPONDÊNCIA: Escola de Enfermagem de Ribeirão Preto - Universidade de São Paulo (EERP-USP).

Av. Bandeirantes, 3900 - 14040-902 - Ribeirão Preto - SP.

Artigo recebido em 09/12/2013 Aprovado para publicação em 06/05/2014 
derivado do cérebro (brain-derived neurotrophic factor - BDNF). ${ }^{10}$ Em estudo referência, detectou-se um SNP deste gene da variante Val66Met, o 196G/ A, em $44 \%$ dos pacientes com TAs e associação entre AN-R e desnutrição. ${ }^{11}$

$\mathrm{O}$ terceiro gene refere-se ao estrogênio (ER â) que é expresso em áreas envolvidas na regulação do apetite. ${ }^{12}$ Nilsson et al. (2004) observaram associação entre SNPs desse gene em pacientes com BN e os SNPs no éxon 5 (1082 G/A) e no éxon 8 (1730 G/A) têm relação com os TAs sinalizando para o desenvolvimento da compulsão alimentar. ${ }^{13}$

Estudos com familiares sugerem que mais de $50 \%$ da etiologia da AN pode ser explicada pelos efeitos genéticos demonstrando que a pesquisa genética molecular é um campo fértil que poderá auxiliar no planejamento de estratégias terapêuticas mais eficazes. $^{14}$

O objetivo desse estudo foi identificar e comparar os SNPs dos genes 5- $\mathrm{HT}_{2 \mathrm{~A}}-1438 \mathrm{G} / \mathrm{A}$, do ER $\beta$ - 1082 G/A (éxon 5) e 1730 A/G (éxon 8), e do BDNF - 196 G/A em pacientes e ex-pacientes com TAs e em jovens saudáveis do sexo feminino.

\section{Metodologia}

Trata-se de estudo clínico, transversal e comparativo, de natureza quantitativa, realizado junto ao Grupo de Assistência em Transtornos Alimentares do Hospital das Clínicas da Faculdade de Medicina de Ribeirão Preto - Universidade de São Paulo (GRATA-HCFMRP - USP), o primeiro serviço especializado criado no Brasil na década de 80 . Uma equipe multiprofissional formada por médicos nutrólogos e psiquiatras, nutricionistas e psicólogos oferece atendimentos em nível ambulatorial, hospital-dia e internação integral para os pacientes, além de grupos de orientação e apoio aos familiares e pacientes. ${ }^{15}$

\section{Participantes e casuística}

Foram formados dois grupos de jovens do sexo feminino:

1. Grupo de pacientes e ex-pacientes portadoras de TA (GP): pacientes portadoras de AN que estavam em tratamento no GRATA-HCFMRP-USP no ano 2010 e por ex-pacientes que foram atendidas pelo serviço (aquelas que perderam o seguimento e que receberam alta). Independentemente da idade e do estado nutricional que elas apresentaram, essa amostra foi definida por conveniência, ou seja, de acordo com a população em seguimento na época da coleta de dados e aquelas que já tiveram atendimento no serviço e que foi possível o contato.

2. Grupo Controle (GC): jovens consideradas saudáveis, com idade semelhante ao GP, obedecendo aos seguintes critérios de inclusão: a) IMC normal para a idade; b) sem parentesco com os sujeitos do GP; c) ausência de sintomas alimentares característicos dos TAs. Para esse último critério, foi aplicado o Eating Atitudes Test (EAT-26), um instrumento autoaplicável ${ }^{16}$, e validado para a população brasileira ${ }^{17}$ que mede sintomas característicos desses quadros de maneira mais fácil e rápida.

O método snowball foi utilizado para recrutamento e seleção desse grupo, ou seja, um grupo de mulheres jovens de mesma faixa etária que não apresentaram sinais ou sintomas dessas doenças, identificados pelo EAT-26.

\section{Critérios de exclusão}

Para os dois grupos, foram excluídas mulheres nas condições de gestação e portadoras de necessidades especiais.

\section{Procedimentos}

Após o convite e aceite das mulheres para participar da pesquisa, as mesmas foram submetidas à avaliação do estado nutricional e determinação dos SNPs. Todos os procedimentos foram realizados no Laboratório de Nutrição do HCFMRP-USP.

Esse projeto foi aprovado pelo Comitê de Ética e Pesquisa do Hospital das Clínicas da Faculdade de Medicina de Ribeirão Preto - USP (protocolo ${ }^{\circ}$ 476/2010).

Para mensuração do peso e estatura, seguiu-se o protocolo sistematizado e calculado o Índice de Massa Corporal (IMC) ${ }^{18,19}$, sendo o EAT-26 aplicado também nos dois grupos.

Para a determinação dos SNPs, colheu-se 10mL de sangue. O DNA foi extraído de leucócitos circulantes pela PCR (reação em cadeia da polimerase), seguida de digestão por enzimas de restrição específicas. As condições da PCR foram as seguintes: uma denaturação inicial de $94^{\circ} \mathrm{C}$ por três minutos, seguidos de 35 ciclos de denaturação a $94^{\circ} \mathrm{C}$ por 15 segundos, em sequência de $55^{\circ} \mathrm{C}$ por 30 segundos, com extensão final de 10 minutos a $72^{\circ} \mathrm{C}$. Os primers utilizados são mostrados abaixo. 


\section{Determinação dos SNPs}

Para o SNP do gene 5- $\mathrm{HT}_{2 \mathrm{~A}}$, a genotipagem do SNP -1438G/A do gene do 5-HT $2 \mathrm{~A}$ foi realizada pela PCR. O DNA genômico foi extraído de leucócitos (100ng em um volume final de $10 \mathrm{~mL}$ ) e amplificado por PCR. As condições de PCR foram: primeiro passo de desnaturação inicial a $94^{\circ} \mathrm{C}$, durante três minutos, seguido por 35 ciclos de desnaturação a $94^{\circ} \mathrm{C}$, durante 15 segundos, de aquecimento, a $55^{\circ} \mathrm{C}$ durante 15 segundos, e extensão a $72^{\circ} \mathrm{C}$ durante 30 segundos, com extensão final de 10 minutos a $72^{\circ} \mathrm{C}$. O produto da PCR foi digerido a $37^{\circ} \mathrm{C}$ por uma noite com $5 \mathrm{U}$ da enzima de restrição $M s p I{ }^{4}$

O alelo -1438G foi cortado em fragmentos com 244 pares de bases (pb) e $224 \mathrm{pb}$, enquanto que o alelo -1438A não foi digerido. Os primers amplificaram um produto de 468 pares de bases. Os fragmentos foram separados em um gel de agarose a $2 \%$. Para a leitura e interpretação desses resultados, seguiu-se o modelo do primer $^{4}$.

O SNP do gene BDNF e seus fragmentos foram amplificados a partir de amostras de DNA pela reação de PCR. As condições de amplificação inicialmente consistiram de quatro minutos de desnaturação a $94 \mathrm{C}^{\circ}, 35$ ciclos de 30 segundos a $94 \mathrm{C}^{\circ}, 30$ segundos à temperatura de anelamento de acordo com a temperatura de fusão de cada primer e 30 segundos a $72 \mathrm{C}^{\circ}$, seguida por uma extensão final de 10 minutos a $74 \mathrm{C}^{\circ}$. Em seguida, três $\mu 1$ do correspondente do produto de PCR foram digeridos durante a noite a $37 \mathrm{C}^{\circ}$, em um volume total de $10 \mu \mathrm{l}$ com $5 \mathrm{U}$ de enzima de restrição NlaIII (Biolabs) para Val66Met e envolvidas em gel de poliacrilamida a $10 \%$.

O produto da PCR foi digerido com a enzima de restrição NlaIII, produzindo quatro fragmentos com $160,59,58$ e $15 \mathrm{pb}$ para o alelo normal e cinco fragmentos com 83, 77, 59, 58 e 15pb para o alelo 196G/ A (Val66Met). Os primers amplificaram um produto de 292 pares de bases. Para a leitura e interpretação desses resultados, seguiu-se o modelo do primer. $^{20}$

Para o SNP do gene ERâ, todas as amplificações das PCR foram amplificadas. Todos os primers foram desenhados no íntron-éxon do gene ERb. ${ }^{13}$

Dois genes de SNPs do ERb foram estudados:

a) $\mathrm{O} \mathrm{G} \rightarrow \mathrm{A}$ com mudança na posição 1082 no éxon 5, criando um local de reconhecimento com a enzima RsaI b) $\mathrm{O} A \rightarrow \mathrm{G}$ com mudança na posição 1730 no éxon 8 , criando um local de reconhecimento com a enzima AluI.

O produto da $\mathrm{PCR}$ foi digerido com as enzimas de restrição $R s a \mathrm{I} e$ AluI. O SNP 1082 G/A do éxon 5 cria um ponto de digestão para a enzima RsaI; o SNP 1730 A/G do éxon 8 cria um ponto de digestão pela enzima AluI. Para a leitura e interpretação desses resultados, seguiu-se o modelo dos primers. ${ }^{13}$

\section{Análise de dados}

O estado nutricional, baseado no IMC foi classificado de acordo com os critérios estabelecidos pela World Healh Organization (WHO) ${ }^{21}$ para os adultos. No caso dos adolescentes, seguiu-se a estratificação segundo percentis obtidos pela curva de IMC para idade. $^{22}$

O resultado do EAT-26 foi obtido pela somatória dos pontos conferidos a cada uma das 26 questões, tipo Likert, tendo como ponto de corte, 21 pontos. Acima desse valor, o teste foi considerado positivo e pode indicar possíveis casos de doença. ${ }^{16}$

Os SNPs dos genes candidatos foram analisados de maneira descritiva, de acordo com a frequência com que apareceram nas amostras coletadas.

Um banco de dados foi elaborado utilizandose a técnica da dupla digitação para minimizar erros na transcrição. O software utilizado foi o Statistical Package for Social Sciences (SPSS), software SPSS, versão 20.0. A normalidade da distribuição das variáveis foi testada por meio do teste não paramétrico de Kolmogorov-Smirnov. ${ }^{23,24}$ Para averiguar se a população estudada apresentava-se em equilíbrio, foi aplicado o teste de equilíbrio de Hardy-Weinberg. ${ }^{25} \mathrm{Em}$ relação às variáveis contínuas (IMC e idade), foi usado o teste ANOVA e, para a variável dicotômica (presença ou não de SNP), o teste qui-quadrado e regressão logística binária. ${ }^{26} \mathrm{O}$ nível de significância considerado foi de á $=0,05$ e o poder dos testes igual a $80 \%$. A análise dos genes foi realizada pelo teste de Genepop (on line).

\section{Resultados}

O GP foi constituído por 29 pacientes do sexo feminino, com diagnóstico de TAs, que estiveram ou estavam em seguimento no GRATA-HCFMRP-USP na época da coleta de dados. Dessas, $10(34,5 \%)$ apresentaram diagnóstico de AN-R, 12 (41,5\%) tinham 
AN-B (anorexia nervosa do subtipo bulímico) e sete (24\%) eram portadoras de BN. O GC foi composto por 78 mulheres saudáveis, seguindo os critérios de inclusão estabelecidos para a pesquisa.

A Tabela 1 mostra os valores de idade, do IMC, do EAT-26 e o diagnóstico clínico dos sujeitos dos GP e GC. As médias de idade para o GP foram de $26 \pm 7$ anos e no GC, $28,6 \pm 6,6$ anos (p=0,274); o IMC no GP foi de $20,8 \pm 4 \mathrm{~kg} / \mathrm{m}^{2}$ e no GC, $21,5 \pm 1,6 \mathrm{~kg} / \mathrm{m}^{2}$ $(\mathrm{p}=0,294)$. O questionário EAT-26 aplicado no GP, teve valor médio de $30 \pm 18,8$ pontos e no GC 7,8 $\pm 4,9$ pontos. Os resultados não revelaram diferença estatística significativa entre os grupos, com exceção do EAT-26 ( $\mathrm{p}=0,000)$, pois foi aplicado no GC com a finalidade de verificar se os escores fossem negativos. Já para o GP, esperava-se que a maioria das pa- cientes apresentasse resultado positivo, mas alguns pacientes e/ou ex-pacientes ( $n=11)$ com quadro clínico estável no momento da coleta de dados, apresentaram resultado negativo para o teste.

Diante dessa diferença entre os grupos, acreditou-se que o EAT-26 poderia ter exercido influência sobre as análises genéticas. Sendo assim, surgiu a necessidade de aplicar, além do teste de qui-quadrado, o teste de regressão logística binária $\left(\mathrm{p}^{\mathrm{a}}\right)$ em todas as análises genéticas, a fim de desmascarar a influência dessa variável.

A Tabela 2 mostra as frequências alélicas dos genes estudados nos grupos (GC e GP). Todos os genes estavam em equilíbrio de Hardy-Weinberg, ou seja, as frequências alélicas em estudo apresentaramse semelhantes entre os grupos.

Tabela 1: Epidemiologia do estudo: idade, estado nutricional (IMC), EAT-26 e diagnóstico dos grupos de pacientes e ex-pacientes (GP) e controle (GC). Ribeirão Preto - SP, 2012

\begin{tabular}{|c|c|c|c|}
\hline & $\mathbf{G P}(n=29)$ & GC $(n=78)$ & $\mathbf{p} \mathbf{X}^{2}$ \\
\hline Idade (anos) & & & 0,274 \\
\hline $15-19$ & 5 & 2 & \\
\hline $20-29$ & 16 & 45 & \\
\hline $30-40$ & 6 & 26 & \\
\hline $41-51$ & 2 & 5 & \\
\hline IMC $\left(\mathrm{kg} / \mathrm{m}^{2}\right)$ adultos & & & 0,294 \\
\hline Desnutrição grave $<16,0$ & 3 & - & \\
\hline Desnutrição leve 17,0 - 18,4 & 4 & - & \\
\hline Eutrofia $18,5-24,9$ & 15 & 76 & \\
\hline Sobrepeso $25-29,9$ & 1 & - & \\
\hline Obesidade moderada $35-39,9$ & 1 & - & \\
\hline \multicolumn{4}{|c|}{ IMC $\left(\mathrm{kg} / \mathrm{m}^{2}\right)$ Crianças/adolescentes } \\
\hline Eutrofia $\geq$ p 3 e $<$ p 85 & 4 & 2 & \\
\hline Sobrepeso $\geq$ p 85 e $<$ p 97 & 1 & - & \\
\hline EAT-26 & & & $0,000 *$ \\
\hline Positivo (> 21 pontos) & 18 & - & \\
\hline Negativo $(<21$ pontos & 11 & 78 & \\
\hline \multicolumn{4}{|l|}{ Diagnóstico } \\
\hline AN-R & 10 & - & \\
\hline AN-B & 12 & - & \\
\hline $\mathrm{BN}$ & 7 & - & \\
\hline
\end{tabular}


Tabela 2: Frequência alélica para cada lócus nos grupos estudados (GP n=29 e GC n=78). Ribeirão Preto - SP, 2012

\begin{tabular}{lccc}
\hline Lócus & Grupos & \multicolumn{2}{c}{ Alelos } \\
\hline & & $\mathrm{G}$ & $\mathrm{A}$ \\
$5 \mathrm{HT}_{2 \mathrm{~A}}$ & $\mathrm{GC}$ & 0,603 & 0,397 \\
& $\mathrm{GP}$ & 0,534 & 0,466 \\
& & $\mathrm{~V}$ & $\mathrm{M}$ \\
& & 0,199 & 0,801 \\
BDNF & $\mathrm{GC}$ & 0,172 & 0,828 \\
& $\mathrm{GP}$ & $\mathrm{G}$ & $\mathrm{A}$ \\
& & 0,955 & 0,045 \\
ER $\beta$ Éxon 5 & $\mathrm{GC}$ & 0,966 & 0,034 \\
& $\mathrm{GP}$ & $\mathrm{G}$ & $\mathrm{A}$ \\
& & 0,423 & 0,577 \\
ER $\beta$ Éxon 8 & $\mathrm{GC}$ & 0,603 & 0,397 \\
\hline
\end{tabular}

Foram também analisadas as distribuições genotípicas para cada gene individualmente. No gene $5 \mathrm{HT}_{2 \mathrm{~A}}$, o genótipo AA possui os dois alelos que contribuem para o risco no desenvolvimento de TA; o genótipo AG apresentou um alelo de risco (A) e o GG não possuía nenhum alelo de risco, não contribuindo portanto, para o desenvolvimento de possíveis casos de TA. Não houve diferença estatística significativa entre os grupos para maior ou menor risco da influência desse gene nesses quadros clínicos (Tabela 3).

Tabela 3

No gene BDNF, o genótipo MM é dominante para o alelo de risco, o genótipo MV apresenta um alelo de risco (M) e o VV não possui nenhum alelo de risco para o desenvolvimento de possíveis casos de TA. Nas análises desse gene, também não houve diferença estatística significativa entre os grupos para maior ou menor risco da influência desse gene nesses quadros clínicos (Tabela 4).

No gene ERb éxon 5, o genótipo GG possui os dois alelos de risco para o possível desenvolvimento de casos de doença, o AG apresenta um alelo de risco

Tabela 3: Distribuição genotípica do gene $5 \mathrm{HT}_{2 \mathrm{~A}}$ nos grupos estudados (GP e GC). Ribeirão Preto - SP, 2012

\begin{tabular}{|c|c|c|c|c|c|}
\hline Genótipos $5 \mathrm{HT}_{2 \mathrm{~A}}$ & $\begin{array}{l}\text { Grupo de pacientes (GP) } \\
\qquad \mathbf{n}=\mathbf{2 9}(\%)\end{array}$ & $\begin{array}{l}\text { Grupo controle (GC) } \\
\qquad \mathbf{n}=\mathbf{7 8}(\%)\end{array}$ & $\mathbf{p} \mathbf{X}^{2}$ & OR $(\operatorname{IC} 95 \%)^{a}$ & $\mathbf{p}^{\mathbf{a}}$ \\
\hline $\mathbf{A A}$ & $5(17,2)$ & $14(17,9)$ & 1,00 & $0,952(0,310-2,930)$ & 0,927 \\
\hline AG & $17(58,6)$ & $34(43,5)$ & 0,195 & $1,833(0,773-4,350)$ & 0,655 \\
\hline GG & $7(24,1)$ & $30(38,4)$ & 0,253 & $0,509(0,194-1,336)$ & 0,552 \\
\hline
\end{tabular}

$\mathbf{p} \mathbf{X}^{2}=$ teste de qui-quadrado simples; $\mathbf{p}{ }^{a}=$ Teste de regressão logística binária; $\mathbf{O R}=$ Odds Ratio; IC = intervalo de confiança.

Tabela 4: Distribuição genotípica do gene BDNF nos grupos estudados (GP e GC). Ribeirão Preto - SP, 2012

\begin{tabular}{cccccc} 
Genótipos BDNF & $\begin{array}{c}\text { Grupo de pacientes (GP) } \\
\mathbf{n = 2 9 ( \% )}\end{array}$ & $\begin{array}{c}\text { Grupo controle (GC) } \\
\mathbf{n}=\mathbf{7 8}(\boldsymbol{\%})\end{array}$ & $\mathbf{p ~ \mathbf { X } ^ { \mathbf { 2 } }}$ & $\mathbf{O R}(\mathbf{I C 9 5 \%})^{\boldsymbol{a}}$ & $\mathbf{p}^{\mathbf{a}}$ \\
\hline MM & $19(65,5)$ & $50(64,1)$ & 1,00 & $1,064(0,435-2,603)$ & 0,592 \\
$\mathbf{M V}$ & $10(34,4)$ & $25(32)$ & 0,820 & $1,116(0,453-2,748)$ & 0,708 \\
$\mathbf{V V}$ & - & $3(3,8)$ & 0,561 & $0,962(0,920-1,005)$ & 0,999 \\
\hline
\end{tabular}

$\mathbf{p} \mathbf{X}^{2}$ = teste de qui-quadrado simples; $\mathbf{p}^{\text {a }}=$ Teste de regressão logística binária; OR = Odds Ratio; IC = intervalo de confiança 
(G) e o AA não possui nenhum alelo de risco. Não houve diferença estatística significativa entre os grupos para maior ou menor risco da influência desse gene nesses quadros clínicos (Tabela 5).

No gene ERb éxon 8, o genótipo AA possui os dois alelos de risco para o possível desenvolvimento de casos de doença, o AG apresenta um alelo de risco (A) e o GG não possui nenhum alelo de risco. $\mathrm{Na}$ análise, também não houve diferença estatística sig- nificativa entre os grupos para maior ou menor risco da influência desse gene nesses quadros clínicos (Tabela 6).

A seguir, foi realizada análise de cada gene unindo os genótipos que possuem os alelos de risco. Tanto no teste de qui-quadrado quanto na regressão logística não houve diferença estatística significativa desses alelos entre os pacientes e indivíduos saudáveis (Tabela 7).

Tabela 5: Distribuição genotípica do gene ERb éxon 51082 G®A nos grupos estudados (GP e GC). Ribeirão Preto - SP, 2012

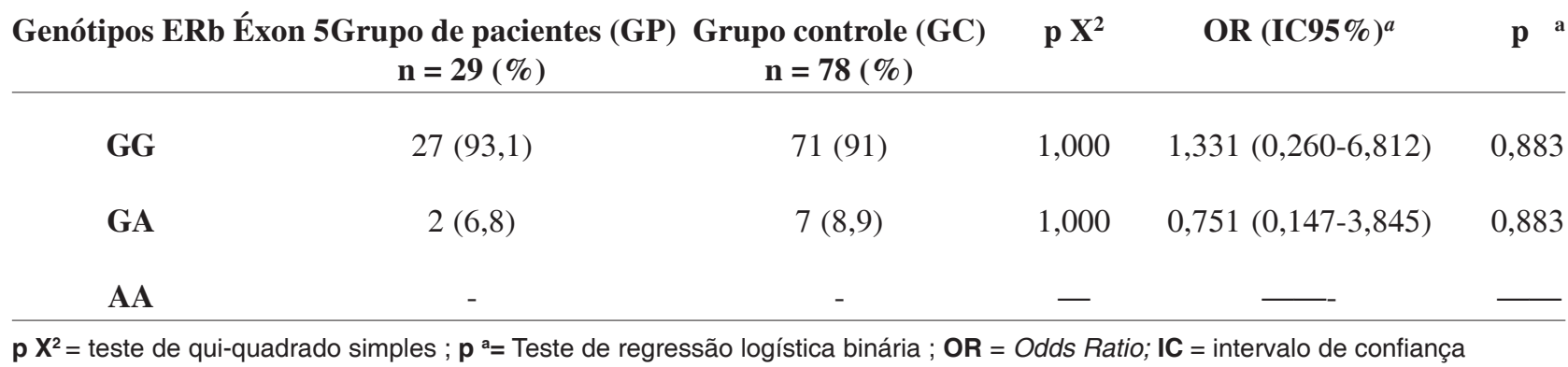

Tabela 6: Distribuição genotípica do gene ERb éxon 81730 A®G nos grupos estudados (GP e GC). Ribeirão Preto - SP, 2012

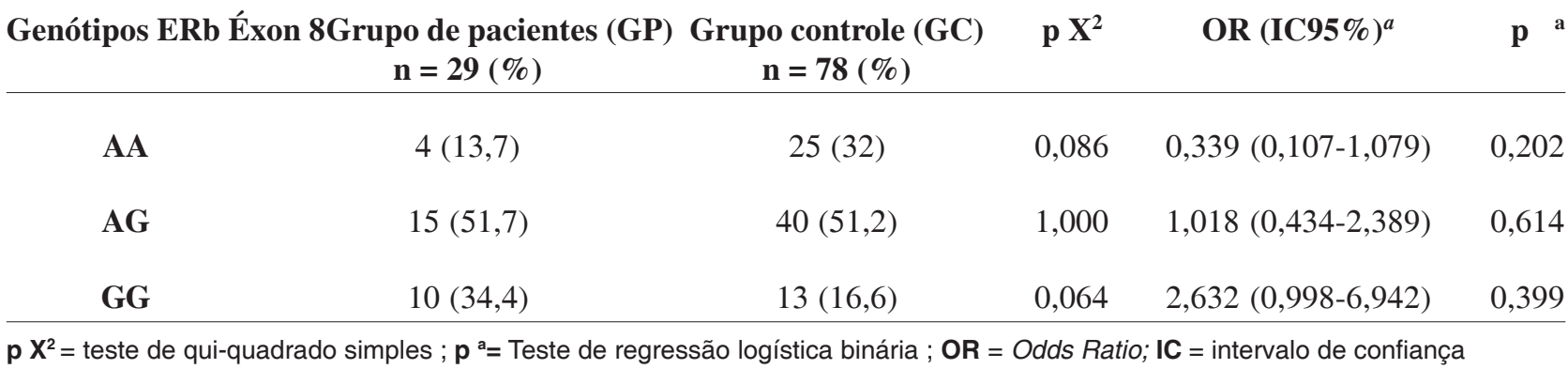

Tabela 7: Análise dos genótipos que possuem alelos de risco nos grupos estudados (GP e GC). Ribeirão Preto - SP, 2012

\begin{tabular}{lccccc}
\hline \multicolumn{1}{c}{ Genótipos } & $\begin{array}{c}\text { Grupo de pacientes }(\mathbf{G P}) \\
\mathbf{n}=\mathbf{2 9}(\boldsymbol{\%})\end{array}$ & $\begin{array}{c}\text { Grupo controle }(\mathbf{G C}) \\
\mathbf{n = 7 8}(\boldsymbol{\%})\end{array}$ & $\mathbf{p ~ X}^{\mathbf{2}}$ & OR $(\mathbf{I C 9 5 \%})^{\mathbf{a}}$ & $\mathbf{p}^{\mathbf{a}}$ \\
\hline $\mathbf{5 H T}_{\mathbf{2 A}}$ GA+AA & $22(75,8)$ & $30(38,4)$ & 0,253 & $1,964(0,748-5,156)$ & 0,552 \\
BDNF MM+MV & $28(96,5)$ & $75(96,1)$ & 1,00 & $1,120(0,112-11,221)$ & 0,362 \\
ER b Éxon 5 GA+AA & $2(6,8)$ & $7(8,9)$ & 1,00 & $0,751(0,147-3,845)$ & 0,883 \\
ER b Éxon 8 GA+AA & $19(65,5)$ & $65(83,3)$ & 0,064 & $0,380(0,144-1,002)$ & 0,399 \\
\hline
\end{tabular}

$\mathbf{p} \mathbf{X}^{2}=$ teste de qui-quadrado simples ; $\mathbf{p}^{\text {a }}=$ Teste de regressão logística binária ; OR = Odds Ratio; $\mathbf{I C}=$ intervalo de confiança 
Uma análise posterior verificou a possível relação entre os indivíduos que eram homozigotos para os alelos de risco em pelo menos dois ou três dos genes em estudo, ou seja, aqueles que possuíam o genótipo sem nenhum alelo de risco e que, teoricamente, estariam protegidos das doenças. Os resultados obtidos indicaram que não houve diferença estatística significativa entre os grupos que pudesse mostrar possível relação desses genes para esses quadros clínicos (Tabela 8).

Uma última análise uniu os indivíduos que possuíam pelo menos um alelo de risco (homozigoto ou heterozigoto) para pelo menos dois dos genes em estudo. Na Tabela 9, são mostradas as análises separadas dos indivíduos que apresentaram alelos de risco de todos os genes estudados (quatro genes); alelos de risco de três genes e alelos de risco de dois genes, ou seja, alelos que poderiam contribuir para o desenvolvimento desses transtornos nos indivíduos analisados. Os dados demonstraram que não houve diferença estatística significativa entre os genes e os alelos de risco que poderiam influenciar no desenvolvimento desses quadros clínicos.

\section{Discussão}

Neste estudo, foram avaliados 29 pacientes e ex-pacientes do sexo feminino com TAs (GP) (10 pacientes com AN-R, 12 pacientes com AN-B e sete pacientes com $\mathrm{BN}$ ) e 78 mulheres saudáveis (GC). As médias de idade e estado nutricional foram semelhantes nos dois grupos e o EAT-26 foi maior no GP $(\mathrm{p}=0,00)$. A população amostral encontrava-se em equilíbrio de Hardy-Weinberg garantindo a confiabilidade dos resultados. Quanto às frequências alélicas e genotípicas e a presença dos alelos de risco, não houve diferença significativa entre os grupos.

Em estudos de associação sobre a base genética dos TAs em relação ao gene $5 \mathrm{HT}_{2 \mathrm{~A}}$ e em sete deles, encontraram resultado significativo para AN. Com exceção desses, todos os outros relatos não demonstraram relação. ${ }^{27}$ Em outra pesquisa, testou-se 5.151 SNPs em 1085 indivíduos com diagnóstico de TAs e 677 indivíduos saudáveis, sem resultado significativo dos SNPs nos alelos. ${ }^{28}$ Da mesma forma, em outros achados, não foram observadas variações no gene do receptor $5 \mathrm{HT}_{2 \mathrm{~A}}$ e da variante do SNP do gene do BDNF (Val66Met) em amostras menores. ${ }^{29}$

Tabela 8: Distribuição de todos os genótipos homozigotos não dominantes nos grupos estudados (GP e GC). Ribeirão Preto - SP, 2012

\begin{tabular}{lccccc}
\hline Genótipos todos & $\begin{array}{c}\text { Grupo de pacientes (GP) } \\
\mathbf{n}=\mathbf{2 9}(\boldsymbol{\%})\end{array}$ & $\begin{array}{c}\text { Grupo controle (GC) } \\
\mathbf{n}=\mathbf{7 8}(\boldsymbol{\%})\end{array}$ & $\mathbf{p ~ \mathbf { X } ^ { \mathbf { 2 } }}$ & OR (IC95\%) & $\mathbf{p}^{\mathbf{a}}$ \\
\hline Homo para 3 genes & - & $4(5,1)$ & 0,572 & - & 0,999 \\
Homo para 2 genes & $7(24,1)$ & $23(29,4)$ & 0,637 & $0,761(0,286-2,027)$ & 0,993 \\
\hline
\end{tabular}

$\mathbf{p} \mathbf{X}^{2}=$ teste de qui-quadrado simples $; \mathbf{p}$ a = Teste de regressão logística binária ; OR = Odds Ratio; IC = intervalo de confiança.

Tabela 9: Distribuição de todos os genótipos e os alelos de risco para a doença nos grupos estudados (GP e GC). Ribeirão Preto - SP, 2012

\begin{tabular}{lccccc}
\hline Genótipos todos & $\begin{array}{c}\text { Grupo de pacientes }(\mathbf{G P}) \\
\mathbf{n = 2 9 ( \% )}\end{array}$ & $\begin{array}{c}\text { Grupo controle (GC) } \\
\mathbf{n}=\mathbf{7 8}(\boldsymbol{\%})\end{array}$ & $\mathbf{p ~ X}^{\mathbf{2}}$ & OR (IC95\%) $)^{a}$ & $\mathbf{p}^{\mathbf{a}}$ \\
\hline Alelo risco 4 genes & - & $3(3,8)$ & 0,561 & - & 0,999 \\
Alelo de risco 3 genes & $16(55,1)$ & $42(53,8)$ & 1,000 & $1,055(0,448-2,485)$ & 0,843 \\
Alelo de risco 2 genes & $26(89,6)$ & $72(92,3)$ & 0,701 & $0,722(0,168-3,099)$ & 0,691 \\
\hline
\end{tabular}

$\mathbf{p} \mathbf{X}^{2}=$ teste de qui-quadrado simples ; $\mathbf{p}$ a= Teste de regressão logística binária ; OR = Odds Ratio; IC = intervalo de confiança 
Corroborando com os estudos acima, pesquisa recente também não encontrou associação entre o SNP do gene do $5 \mathrm{HT}_{2 \mathrm{~A}}$ com o IMC dos pacientes ( $\mathrm{p}=0,393$, $\mathrm{OR}=1,2255$ ), apesar dos dados apoiarem o papel significativo do alelo A como fator de risco para AN. ${ }^{30}$ Em outro estudo, ao estimar a prevalência desse SNP em 182 pacientes japoneses com TAs, observou que a frequência do alelo $\mathrm{G}$ do lócus $5 \mathrm{HT}_{2 \mathrm{~A}}$ foi muito maior naqueles com TA do que no grupo controle (GC), cuja diferença na frequência do alelo $\mathrm{G}$ foi de $0,09(0,55-0,46)$. Nos pacientes com BN, a frequência do alelo $\mathrm{G}$ foi muito mais elevada do que no $\mathrm{GC}$ $(0,10 ; 0,56-0,46)$. Concluiu-se que o número amostral foi insuficiente para observar fielmente as interações de associações entre o gene $5 \mathrm{HT}_{2 \mathrm{~A}}$ e os TAs. ${ }^{31}$

Em relação ao gene BDNF no presente estudo, quando separados seus genótipos em homozigoto e heterozigoto, em especial para o homozigoto VV (que não contribui para o desenvolvimento da doença), esse se manteve em apenas $3,8 \%$ dos controles $\left(\mathrm{pX}^{2}=0,561\right.$; OR=0,962; IC 95\%=0,920-1,005 com regressão logística de 0,999$)$. Para todos os resultados, os valores estatísticos não foram significativos.

Em recente investigação com 110 pacientes com TAs do sexo feminino, observou-se que aquelas com BN apresentaram maior transmissão de alelos com níveis muito altos do $\operatorname{BDNF}(10,7 \%)$ da variabilidade genética $(p=0,016)$. Os valores estatísticos foram diferentes na comparação entre a $\mathrm{AN}$ e $\mathrm{BN}(\mathrm{p}<0,025)$, no entanto, ao dividir por subtipos (AN-B, AN-R, BN), não ocorreu significância estatística na associação do $\mathrm{SNP}$ com o grupo AN-R e BN $(\mathrm{p}=0,008) .^{32}$

Em outro estudo, investigou-se 114 pacientes com AN e os pais, os resultados também não foram significativos em relação ao alelo 66Met do BDNF e AN $(\mathrm{OR}=0,84$; IC 95\% $=0,43-1,62) .{ }^{33}$

Outros pesquisadores também investigaram 258 alunos espanhóis de ambos os sexos e observou-se alta porcentagem da presença do SNP_Val66Met (G196A) do gene do BDNF (33,7\%, IC 95\%:27,1$40,2)$, porém sem resultados estatisticamente significativos. ${ }^{34}$

Indo de encontro a esses resultados, pesquisadores analisaram o alelo Met66 do SNP Val66Met do gene do BDNF em 689 pacientes japonesas do sexo feminino com AN e BN e 573 mulheres saudáveis. A frequência alélica do Met66 no grupo controle foi de 0,421 ( $\mathrm{a}=0,0125)$, sem diferença também em análises de associação separadas. Todos esses achados trazem resultados semelhantes demostrando que os dados são limitados ao número relativamente pequeno de famí- lias não existindo relação direta entre a presença de SNP e os TAs. Assim, a variabilidade e o papel do gene do BDNF nos TAs em futuras pesquisas poderão elucidar o que essas variáveis podem causar e revelar se esse gene é um marcador biológico da doença, além das interações gene/ambiente e gene/gene que provavelmente dificultam esses achados..$^{32-35}$

A análise do SNP do gene ERb no presente estudo demonstrou que os resultados não apresentaram diferenças significativas entre os grupos estudados para o SNP 1730A ${ }^{\circledR} G$, tanto no genótipo AA $\left(\mathrm{pX} \mathrm{X}^{2}=0,086\right)$ quanto no genótipo $\mathrm{GG}\left(\mathrm{pX}^{2}=0,064\right)$. Esses achados corroboram outros dados da literatura.

Um deles foi realizado com 170 pacientes anoréxicas do sexo feminino caucasianas e $152 \mathrm{mu}-$ lheres saudáveis, analisou-se os SNPs do receptor do estrogênio I (ESR1), éxon 2, e receptor do estrogênio II (ESR2), éxons 5 e 8. Não houve diferença significativa entre os grupos $\left(\mathrm{x}^{2}=8,04, \mathrm{p}>0,2\right)$, mesmo avaliados separadamente $\left(x^{2}=2,60, p>0,2\right)$, inclusive para a frequência alélica. ${ }^{36}$ Outros autores também naõ encontraram associação entre os SNPs do gene ERb (1730 A®G e $1082 \mathrm{G} \AA A)$ em 76 mulheres suecas com $\mathrm{BN}$ e 60 mulheres saudáveis, onde as frequências alélicas e genotípicas no SNP $1082 \mathrm{G} \AA \mathrm{A}\left(\mathrm{x}^{2}=1,81\right.$; $\mathrm{p}>0,05$ e $\mathrm{OR}=2,85)$ e no SNP $1730 \mathrm{~A} \otimes \mathrm{G}\left(\mathrm{x}^{2}=9,04\right.$; $\mathrm{p}=0,0026$ e $\mathrm{OR}=2,20)$ não apresentaram diferença estatística. ${ }^{13}$

$\mathrm{Na}$ mesma linha de pesquisa, autores investigaram 348 mulheres francesas e 41 mulheres alemãs com AN e 613 pais, sendo o grupo controle composto por 567 mulheres saudáveis. Eles observaram que o gene do ESR1 apresentou diferença significativa nos pacientes com AN-R e nenhuma associação entre os SNPs e a AN. ${ }^{37}$

Essas investigações vêm de encontro aos achados do presente trabalho ao verificar que não houve associação entre a presença de SNPs dos genes $5 \mathrm{HT}_{2 \mathrm{~A}}$, BDNF e ERb e o risco de TAs.

Algumas limitações do presente estudo assim como na área de pesquisa genética nos TAs devem ser apontadas, entre elas, o tamanho da amostra, que deve ser maior a fim de realizar estudos de mega e metanálise. Outros fatores incluem a baixa idade dos participantes e a baixa prevalência da doença na população. A estratificação por etnia e sexo traz probabilidade de resultado falso positivo e normalmente não acontece a replicação dos dados. Portanto, novos estudos nessa direção deverão ser realizados para possibilitar melhores respostas e novas estratégias para o tratamentos de TAs. 


\begin{abstract}
Objective: to identify polyphormisms (SNPs) of the 5-HT ${ }_{2 A}$, BDNF and ERâ genes in 29 patients with Eating Disorders (EDs) cared for by a specialized service and 78 healthy women. Method: age, weight, and height were collected to compute Body Mass Index; the Eating Attitudes Test (EAT-26) was applied; and the participants' SNPs were determined. The allele and genotype frequency of genes was computed and an analysis linking the genotypes that possessed risk alleles was performed for each gene. Results: There were significant differences in terms of age, nutritional state, and presence of risk alleles between the groups $\left(5 \mathrm{HT}_{2 \mathrm{~A}}\right.$ : OR=1.964; BDNF: OR=1.120; ERb exon 5: OR=0.751 and exon 8: OR=0.380). Conclusion: The heterogeneity of the Brazilian population, low incidence of the disease, and small sample may have influenced the results and further research is needed to clarify the role genetics play in the etiology of EDs.
\end{abstract}

\title{
Keywords: Eating Disorders. Polymorphism, Genetic. Genes. Anorexia Nervosa. Bulimia Nervosa.
}

\section{Referências}

1. Cordás TA, Salzano FT. Aspectos gerais dos transtornos alimentares: características, critérios, diagnósticos, epidemiologia e etiologia. In: Alvarenga M, Scagliusi FB, Philippi ST, organizadores. Nutrição e transtornos alimentares: avaliação e tratamento. São Paulo: Manole; 2011. p. 5-15.

2. Jacobi C, Hayward C, Zwaan M, Kraemer HC, Agras WS. Coming to terms with risk factors for eating disorders: application of risk terminology and suggestions for a general taxonomy. Psychol Bull. 2004; 130: 19-65.

3. Klump KL, Gobrogge KL. A review and primer of molecular genetic studies of anorexia nervosa. Int J Eat Disord. 2005; 37: S43-8.

4. Collier DA, Jaraz MJ, Li T, Mupita D, Brown N, Treasure J. Association between $5-\mathrm{HT}_{2 \mathrm{~A}}$ gene polymorphism and anorexia nervosa. Lancet. 1997; 350: 412.

5. Kipman A, Bruins-Slot L, Boni C, Hanoun N, Adès J, Blot P, et al. 5-HT(2A) gene promoter polymorphism as a modifying rather than a vulnerability factor in anorexia nervosa. Eur Psychiatry. 2002; 17: 227-9.

6. Ribasés M, Gratacòs M, Fernández-Aranda F, Bellodi L, Bon $\mathrm{C}$, Anderluh $\mathrm{M}$, et al. Association of BDNF with anorexia, bulimia and age of onset of weight loss in six European populations. Hum Mol Genet. 2004; 13: 1205-12.

7. Treasure J, Owen JB. Intriguing links between animal behavior and anorexia nervosa. Int J Eat Disord. 1997; 21: 307-11.

8. Aubert R, Betoulle D, Herbeth B, Siest G, Fumeron F. 5'-HT2A receptor gene polymorphism is associated with food and alcohol intake in obese people. Int J Obes Relat Metab Disord. 2000; 24: 920-4.

9. Steiger $\mathrm{H}$. Eating disorders and the serotonin connection: state, trait and development effects. J Psychiatry Neurosci. 2004; 29: 20-9.

10. Hinney A, Barth N, Ziegler A, von Prittwitz S, Hamann A, Hennighausen $\mathrm{K}$, et al. Serotonin transporter gene-linked polymorphic region: allele distributions in relationship to body weight and in anorexia nervosa. Life Sci. 1997; 61: PL295303.

11. Maisonpierre PC, Le Beau MM, Espinosa R 3rd, Ip NY, Belluscio L, de la Monte SM, et al. Human and rat brainderived neurotrophic factor and neurotrophin-3: gene structures, distributions, and chromosomal localizations. Genomics. 1991; 10: 558-68.
12. Klump KLB, Miller PK, Keel M, McGue, IWG. Genetic and environmental influences on anorexia nervosa syndromes in a population-based twin sample. Psychol Med. 2001; 31: 73740.

13. Nilsson $M$, Naessén $S$, Dahlman I, Lindén Hirschberg A, Gustafsson JA, Dahlman-Wright K. Association of estrogen receptor $B$ gene polymorphisms with bulimic disease in women. Mol Psychiatry. 2004; 9: 28-34.

14. Pinheiro PP, Sullivan PF, Bacaltchuck J, Prado-Lima PAS, Bulik CM. Genetics in eating disorders: extending the boundaries of research. Rev Bras Psiquiatr 2006; 28: 218-25.

15. Santos JE. Grata: nossa história, trabalho e desafios. Medicina (Ribeirão Preto). 2006; 39: 323-6.

16. Garner DM, Garfinkel PE. The eating attitudes test: an index of the symptom of anorexia nervosa. Psychol Med. 1979; 9: 273-9.

17. Bighetti F, Santos CB, Santos JE, Santos JE, Ribeiro RPP. Tradução e validação do Eating Attitudes Test em adolescentes do sexo feminino de Ribeirão Preto, São Paulo. J Bras Psiquiatr. 2004; 53: 339-46.

18. Blackburn GL, Thornton PA. Nutritional assessment of the hospitalized patients. Med Clin North Am 1979; 63: 1110315.

19. Ministério da Saúde (BR). Sistema de Vigilância Alimentar e Nutricional - SISVAN: orientações básicas para a coleta, o processamento, a análise de dados e a informação em serviços de saúde. Brasília, DF: Ministério da Saúde; 2004. (Série A. Normas e manuais técnicos).

20. Ribasés M, Gratacòs M, Armengol L, Cid R, Badia A, Jimémez $\mathrm{L}$, et al. Met66 in the brain-derived neurotrophic factor (BDNF) precursor is associated with anorexia nervosa restrictive type. Mol Psychiatry. 2003; 8: 745-51.

21. World Health Organization. The world health report 1998: life in the 21st century: a vision for all. Geneva: WHO; 1998.

22. Sistema de Vigilância Alimentar e Nutricional (BR). Incorporação das curvas de crescimento da Organização Mundial da Saúde de 2006 e 2007 no SISVAN. Brasília, DF: SISVAN; 2009 [cited 2012 Set 10]; Available from: http:// nutricao.saude.gov.br/documentos/sisvan_norma_tecnica_ criancas.pdf.

23. Sheskin DJ. Handbook of parametric and nonparametric statistical procedures, 3rd ed. Florida: Chapman \& Hall/CRC; 2004.

24. Shibasaki T, Siegel S. Estatística não-paramétrica para as ciências do comportamento. São Paulo: McGraw-Hill; 1975. 
25. Strachan T, Read AP. Genes in pedigress. In: Strachan T, Read AP, editors. Human molecular genetics. 2nd ed. New York: Wiley-Liss; 1999. p. 55-70.

26. International Business Machines. SPSS Incorporation. SPSS for Windows: Statistical Package for the Social Sciences. Release 20.0. Chicago: SPSS; 2011.

27. Klump KL, Culbert KM. Molecular genetic studies of eating disorders current status and future directions. Curr Dir Psychol Sci. 2007; 16: 37-41.

28. Pinheiro AP, Bulik CM, Thornton LM, Sullivan PF, Root TL, Bloss CS, et al. Association study of 182 candidate genes in anorexia nervosa. Am J Med Genet B Neuropsychiatr Genet 2010; 153B: 1070-80.

29. Scherag S, Hebebrand J, Hinney A. Eating disorders: the current status of molecular genetic research. Eur Child Adolesc Psychiatry. 2010; 19: 211-26.

30. Martaskova D, Šlachtova L, Kemlink D, Zahorakova D, Pape•ova H. Polymorphisms in serotonin-related genes in anorexia nervosa. The first study in Czech population and metaanalyses with previously performed studies. Folia Biol (Praha). 2009; 55: 192-7.

31. Nishiguchi N, Matsushita A, Suzuki K, Murayama M, Shirakawa $\mathrm{O}$, Higuchi S. Association between 5HT2A receptor gene promoter region polymorphism and eating disorders in Japanese patients. Biol Psychiatry. 2001; 50: 123-8.

32. Mercader JM, Ribasés M, Gratacós M, González JR, Bayés M, Cid R, et al. Altered brain-derived neurotrophic factor blood levels and gene variability are associated with anorexia and bulimia. Genes Brain Behav. 2007; 6: 706-16.
33. Dardennes RM, Zizzari P, Tolle V, Foulon C, Kipman A, Romo $\mathrm{L}$, et al. Family trios analysis of common polymorphisms in the obestatin/ghrelin, BDNF and AGRP genes in patients with Anorexia nervosa: Association with subtype, body-mass index, severity and age of onset. Psychoneuroendocrinology. 2007; 32: 106-13.

34. Arija V, Ferrer-Barcala M, Aranda N, Canals J. BDNF Val66Met polymorphism, energy intake and BMI: a follow-up study in schoolchildren at risk of eating disorders. BMC Public Health [serial online] 2010 [cited 2012 Jul 3]; 10. Available from http:/ /www.biomedcentral.com/1471-2458/10/363.

35. Ando T, Ishikawa T, Hotta M, Naruo T, Okabe K, Nakahara T, et al. No association of brain-derived neurotrophic factor Val66Met polymorphism with anorexia nervosa in Japanese. Am J Med Genet Neuropsychiatr Genet Part B. 2012; 159B: 48-52.

36. Eastwood $\mathrm{H}$, Brown KMO, Markovic D, Pieri LF. Variation in the ESR1 and ESR2 genes and genetic susceptibility to anorexia nervosa. Mol Psychiatry. 2002; 7:86-9.

37. Versini A, Ramoz N, Strat YL, Scherag S, Ehrlich S, Boni C, et al. Estrogen receptor 1 gene (ERS1) is associated with restrictive anorexia nervosa. Neuropsychopharmacol. 2010; 35: 1818-25. 